\title{
Correlation between Von Spee's Curve and Vertical Dental Eruptions in Class II Division-2 Malocclusion
}

\author{
Dr Muhammad Azeem,' Dr Waheed Ul Hamid,2 Dr Arfan UI Haq,3 Dr Huma ljaz \\ 'Asst Prof, ${ }^{2,3}$ Prof, ${ }^{4 R e s i d e n t, ~ D e p t ~ o f ~ O r t h o d o n t i c s, ~ d e ' M o n t m o r e n c y ~ C o l l e g e ~ o f ~ D e n t i s t r y ~}$ \\ Faisalabad Medical University, Pakistan
}

Correspondence: Dr Muhammad Azeem; Email: dental.concepts@hotmail.com

\section{ABSTRACT}

Introduction: Von Spee's curve is one of the important treatment aspects in orthodontics. Any orthodontic treatment planning is dependent on this key factor.

Objective: To find out the correlation between the Von Spee's curve and occlusal eruption of anterio-posterior teeth in Class II Division 2 malocclusion.

Materials \& Method: Current research was conceived at the Department of Orthodontics, de'Montmorency College of Dentistry and Faisalabad Medical University. Two hundred and fifty Class II Division 2 patients (112 male, mean age: $15.1 \pm 1.5$ years; 138 female, mean age: 15.4 1.3 years) were included. Depth of the curve was calculated on lateral cephalograms and dental plaster models, and correlated with the vertical eruption of lower incisal teeth and posterior mandibular molars.

Result: The mesiobuccal site of mandibular first molar was the deepest part of Von Spee's curve, and vertical eruption of lower incisal teeth were more related to depth of Von Spee's curve as compared to vertical eruption of mandibular molars.

Conclusion: Vertical eruption of the mandibular molar teeth make significant contribution to the depth of Von Spee's curve in Class II Division 2 malocclusion.

Keywords: Class II Division 2, Von Spee's curve, vertical eruption

\section{INTRODUCTION}

The Von Spee's Curve (VSC), named after the embryologist 'Ferdinand Graf Von Spee', can be described as the tangent line to the frontal portion of the mandibular condyle, the upper surface of mandibular posterior molars, and the incisal edges of the mandibular incisal teeth. ${ }^{\prime}$ VSC is usually determined by vertical eruption of anterior and/or posterior teeth in any class of malocclusion. ' Vertical skeletal pattern, type of masticatory pattern and amount of deep bite or open bite are also reported to be the determinants of VSC. ${ }^{2}$ The VSC of $1 \mathrm{~mm}$ per side is considered to be normal in any individual and this depth can be linked to the differential eruption timing of maxillary and mandibular teeth which allows unopposed vertical eruption of mandibular teeth. ${ }^{3}$

The Von Spee's curve is not without significance, it is important for the integrity of stomatognathic system and functional occlusion by absorbing the occlusal masticatory forces during functional movements of lower jaw in three planes of space. It is also reported to be associated with three dimensional freedom of mandibular movement. It has been found that as the VSC deepens, amount of vertical and horizontal overlapping of incisors also increases. ${ }^{4}$

Flattening of VSC is one the six keys of Andrew's ideal occlusion. ${ }^{5}$ Various investigators described VSC in different ways. According to Hemley, VSC is two bicuspids locked below the occlusal table between the mesially tipped mandibular molars and distally tipped mandibular anterior teeth. ${ }^{6}$ As per Strang and Thompson, VSC is a result of over-erupted mandibular incisal teeth, mesial inclination of lower molars and vertical position of premolars below the occlusal plane.?

Various management strategies have been proposed in literature regarding management of VSC. Burstone and Schudy suggested the management of VSC by lowering the mandibular incisal teeth, extrusion of lower molars, or any such combination. ${ }^{8,9}$ Before opting for the best management option it is important to know the real etiology of VSC in any class of malocclusion. ${ }^{10}$ 


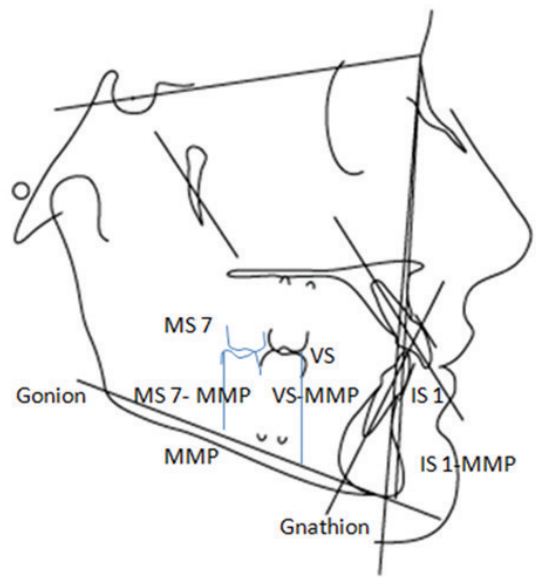

Figure 1: Cephalometric reference points and planes

Therefore, the objective of current research was to find out the correlation between Von Spee's curve and occlusal eruption of anterio-posterior teeth in Class II Division 2 malocclusion.

\section{MATERIALS AND METHOD}

This cross sectional study was conducted at the Department of Orthodontics, de'Montmorency College of Dentistry \& Faisalabad Medical University from January 2016 to July 2017 after receiving institutional approval. Two hundred and fifty Class II Division 2 patients ( 112 male, mean age: $15.1 \pm .5$ years; 138 female, mean age: $15.4 \pm 1.3$ years) were included.

Following patients were selected: Class II Division 2 malocclusion, age range 12-20 years, arch length discrepancy $0 \pm 2 \mathrm{~mm}$, all teeth erupted excluding third molars. The subjects were excluded having previous history of orthodontic therapy or oral surgery, and poor quality treatment records.

VSC depth was calculated on plaster casts using Veli's method," in which horizontal line was drawn from the incisal edges of lower incisal teeth to the distobuccal cusp tip of lower second molar and measuring of the perpendicular distance from this horizontal reference line to the buccal cusp tip of the deepest involved tooth of right and left side.

All lateral cephalograms were traced manually by one investigator using various reference points and planes (Figure 1). Cephalometric reference points and planes used were:

IS1: Tip of the lower central incisors

MS7: Distobuccal cusp tip of lower second molar
MMP: Mandibular plane line joining gonion and gnathion

LS1-MMP: Perpendicular distance from tip of IS 1 to MMP MS7-MMP: Perpendicular distance from distobuccal cusp tip of MS7 to MMP

VS-MMP: Perpendicular distance from the deepest of VS to MMP

The data were analyzed using SPSS version 21.0. The descriptive statistics of the perpendicular measurements on lateral cephalograms were calculated and tabulated. Linear regression was used to find out the Pearson's correlation coefficient for establishing of correlation between the depth of VSC (VS-MMP) to the vertical eruption of lower second molars (MS7-MMP/VS-MMP) as well as depth of VSC (VS-MMP) to vertical eruption of the lower incisal teeth (LS1-MMP/VS-MMP). Paired t-test was used for right versus left side comparisons of VSC values; $p<0.05$ was considered as statistically significant.

\section{RESULT}

Values of the calculations on cephalograms are presented in Tablel. The multiple linear regression analysis showed that MS7-MMP/VS-MMP had a significant correlation to the depth of VSC in Class II Division 2 malocclusion (Table 2).

Mesiobuccal cuspal area of the lower first molar was the deepest area of VSC with a maximum depth of $2.33 \pm 0.44 \mathrm{~mm}$ and a minimum depth of $1.55 \pm 0.66$. The paired t- test showed no significant difference in VSC depth between the two sides (Table 3).

Strong negative correlation ( $r$-value near to -1) indicated inversely related to more vertical eruption of teeth. 
Table 1: Vertical eruption of teeth and VSC depth

\begin{tabular}{|l|c|c|c|c|}
\hline \multicolumn{1}{|c|}{ Variable } & Mean $(\mathbf{m m})$ & SD & Maximum & Minimum \\
\hline MS7-MMP & 43.5673 & 1.5455 & 45.5673 & 41.6780 \\
\hline LS1-MMP & 39.7890 & 1.5666 & 41.1231 & 37.3455 \\
\hline VS-MMP & 35.0323 & 1.1112 & 36.7677 & 35.1222 \\
\hline
\end{tabular}

Table 2: Correlation between vertical eruption of teeth and VSC depth

\begin{tabular}{|l|c|c|}
\hline \multicolumn{1}{|c|}{ Variable } & Deviation Scores & Coefficient of Deter?mination (r-value) \\
\hline MS7-MMP/VS-MMP & 27.45 & 0.410 \\
\hline LS1-MMP/VS-MMP & 10.32 & 0.110 \\
\hline
\end{tabular}

$r=$ or near to 1: strong positive correlation

$r=$ or near to -1: strong negative correlation

Table 3: Right versus left side of VSC

\begin{tabular}{|l|c|c|c|c|c|}
\hline Mean $(\mathbf{m m})$ & SD & Side Difference & Standard Error & t-Value & $\boldsymbol{p}$-Value \\
\hline 2.321 & 0.453 & -0.069 & 0.078 & -0.811 & 0.331 (NS) \\
\hline
\end{tabular}

NS: Not significant

\section{DISCUSSION}

The Von Spee's curve has very important role in maintaining the integrity of stomatognathic system by absorbing the occlusal and masticatory forces during functional movements of lower jaw in three planes of space. Thus its evaluation is very important while planning any orthodontic case. ${ }^{12}$

The current study compared right and left sides of VSC values and results showed no significant difference in VSC depths, which is in agreement with the finding of studies by Marshall et $a{ }^{2}$ and Veli et $a l .{ }^{11}$ In the present study, the mesiobuccal cuspal area of lower first molar was the deepest part of VSC, which is in agreement with the findings of Veli et al. ${ }^{11}$

Result of current research is also in agreement with the findings of Imtiaz et $\mathrm{al}^{13}$ and Nayar et $\mathrm{al}^{1{ }^{14}}$ who concluded that VSC was deepest in Class II Division 2 maloclussion. According to Veli et al," the curve of Spee depth in Class II Division 2 malocclusion was more associated with vertical eruption of mandibular posterior teeth. The current findings also showed similar correlation between the vertical eruption of posterior teeth and VSC depth in Class II Division 2 malocclusion. These results can be linked to the fact that anterior teeth have vertical stop in Class II Division 2 malocclusion, thus their discontinued eruption does not contribute to the deepening of incisal aspect of VSC.

In the present research, no attempt was made to differentiate the gender groups because of the reported lacking of gender dimorphism in the depth of VSC. ${ }^{15-17}$ Limitations of current study were its cross sectional design, short study duration and small sample size. Further large scale study with a longitudinal study design is suggested to better understand the development of VSC in Class II Division 2 malocclusion.

\section{CONCLUSION}

Vertical eruption of mandibular posterior teeth make a significant contribution to the depth of Von Spee's curve in Class II Division 2 malocclusion. 


\section{REFERENCES}

1. Braun S, Hnat WP, Johnson BE. The curve of Spee revisited. Am J Orthod Dentofac Orthop. 1996;1 10(2):206-10.

2. Marshall SD, Caspersen M, Hardinger RR, Franciscus RG, Aquilino SA, Southard TE. Development of the curve of Spee. Am J Orthod Dentofac Orthop. 2008; 134(3):344-52.

3. Carlsen DB, Meredith HV. Biologic variation in selected relationships of opposing posterior teeth. Angle Orthod. 1960; 30(3):162-73.

4. Kanavakis $G$, Mehta $N$. The role of occlusal curvatures and maxillary arch dimensions in patients with signs and symptoms of temporomandibular disorders. Angle Orthod. 2013; 84(1):96-101.

5. Andrews FL. The six keys to normal occlusion. Am J Orthod. 1972; 62(3):296-309.

6. Hemley S. Bite plates, their application and action. Am J Orthod. 1938; 24(8):721-36.

7. Strang RHM, Thompson WM. Case analysis. Textbook of Orthodontia. Philadelphia: Lea and Febiger; 1958. p.335-61.

8. Burstone CR. Deep overbite correction by intrusion. Am J Orthod. 1977; 72(1):1-22.

9. Schudy FF. The control of vertical overbite in clinical orthodontics. Angle Orthod. 1968; 38(1):19-38.

10. Veli L, Ozturk MA, Uysal T. Curve of Spee and its relationship to vertical eruption of teeth among different malocclusion groups. Am J Orthod Dentofac Orthop. 2015; 147(3):305-12.

11. Rozzi M, Mucedero M, Pezzuto C, Cozza P. Leveling the curve of Spee with continuous archwire appliances in different vertical skeletal patterns: A retrospective study. Am J Orthod Dentofac Orthop. 2017; 151 (4):758-66.

12. Nardone J. Leveling of the curve of Spee [thesis]. Toronto, Ontario, Canada: University of Toronto; 2012.

13. Imtiaz A, Rozina N, Gul ER, Tabassum A. Influence of malocclusion on the depth of curve of Spee. J Pak Med Assoc 2011; 61 (11):1056.

14. Nayar S, Dinakarsamy V, Santhosh S. Evaluation depth of the curve of Spee in Class I, Class II, and Class III malocclusion: A cross sectional study. J Pharma Bioallied Sci. 2015; 7(Suppl 1):92-4.

15. Negi SK, Shukla L, Sandhu GPS, Aggarwal M. Investigation of variation in curve of Spee, over jet and overbite among Class I and Class II malocclusion subjects and to find sexual dimorphism, if any. J Adv Med Dent Scie Res. 2016; 4(1):21-6.

16. Haq AU, Azeem M. Correlation between curve of Spee and vertical eruption of anterior or posterior teeth in Class II Division I. Pak Oral Dent J. 2015; 35(4):610-4.

17. Jhalani A, Golchha V, Paul R, Sharma P. Deepbite malocclusion: Analysis of underlying components in different facial growth patterns. J Dent App. 2015; 2(3):183-7. 